\title{
Focused Assessment with Sonography in Trauma (FAST) Examina- tion in a Patient with Situs Inversus and Splenic Contusion
}

\author{
Antonio E Muñiz, MD, FACEP, FAAP* \\ Dallas Regional Medical Center, Mesquite, TX, USA
}

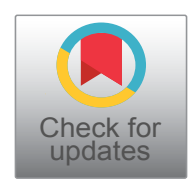

*Corresponding author: Antonio E Muñiz, MD, FACEP, FAAP, Dallas Regional Medical Center, 827 Via Del Sur, Mesquite, TX 75150, USA, Tel: (832)-389-7631

\begin{abstract}
Background: Situs inversus totalis is a rare anatomic anomaly in which the normal arrangement of the heart and viscera is reversed to form a mirror picture of their usual anatomic position. It typically poses a diagnostic dilemma during the initial assessment acute thoracoabdominal trauma.

Case report: A case is presented of the findings found on the focused assessment with sonography in trauma (FAST) examination of a young adult with situs inversus who sustained solid organ injury from blunt trauma.

Conclusion: Patients with situs inversus can be a challenge to physicians both diagnostically and therapeutically as these patients may have nontraditional signs and symptoms upon presentation. Expedient diagnosis of solid organ injury in these patients is important, since treatment may be affected according to which organ is injured.
\end{abstract}

\section{Keywords}

Ultrasound, FAST examination, Splenic injury, Splenic hematoma, Splenic contusion, Situs inversus

\section{Introduction}

Situs inversus totalis is a rare anatomic anomaly. The estimated prevalence of situs inversus varies among different populations but is generally $k 1$ in 10,000 people, with a range of $1: 5,000$ to $1: 20,000$ ) and [1-3]. Situs inversum viscerum is that condition in which the normal arrangement of the viscera is reversed to form a mirror picture of their usual anatomic position. Visceral situs inversus can occur with or without dextrocardia. If the heart is located in the right side of the thorax, it is known as situs inversus totalis [4]. If the heart remains in the normal left side of the thorax, a much rarer condition, it is known as situs inversus with levocardia or situs inversus incompletu [5]. Situs inversus results from abnormal rotation of the primitive cardiac tube during embryogenesis of unknown mechanism and may complicate diagnosis and management of acute abdominal trauma. Patients with undiagnosed situs inversus can be a challenge to physicians both diagnostically and therapeutically as these patients may have nontraditional signs and symptoms upon presentation. We present the case of a young adult with situs inversus who sustained solid organ injury from blunt trauma and review the findings of the focused assessment with sonography in trauma (FAST) examination in this patient.

\section{Case Report}

A 24-year-old male was a restrained driver in an automobile accident. He had a frontal impact at $65 \mathrm{mph}$ and the air bag did release. The emergency medical services (EMS) immobilized him in a cervical collar and long spine board. He was transported to the emergency department. He complained of chest and abdominal pain. His past medical history included situs inversus totalis. He took no medications and was allergic to sulfa medications. He denied alcohol or illicit drug use and did not smoke.

He had a temperature of $36.8^{\circ} \mathrm{C}$, blood pressure of $96 / 68 \mathrm{mmHg}$, heart rate of $89 /$ minute, and a respiratory rate of $16 /$ minute. He was in mild distress. His head examination was normal. His neck examination revealed no tenderness of deformities. He had a contusion over his right chest from the seat belt with no deformity or

Citation: Muñiz AE (2019) Focused Assessment with Sonography in Trauma (FAST) Examination in a Patient with Situs Inversus and Splenic Contusion. Trauma Cases Rev 5:075. doi.org/10.23937/24695777/1510075

Accepted: May 28, 2019: Published: May 30, 2019

Copyright: (C) 2019 Muñiz AE. This is an open-access article distributed under the terms of the Creative Commons Attribution License, which permits unrestricted use, distribution, and reproduction in any medium, provided the original author and source are credited. 


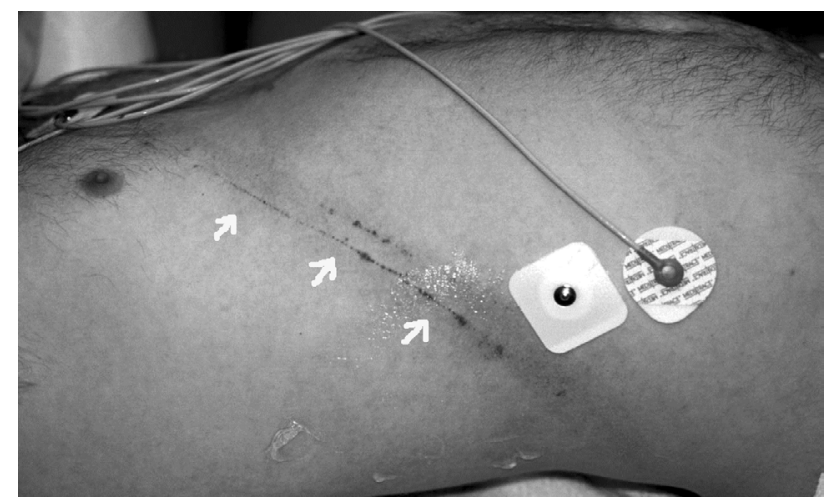

Figure 1: Contusion over the right chest from the seat belt (arrows).

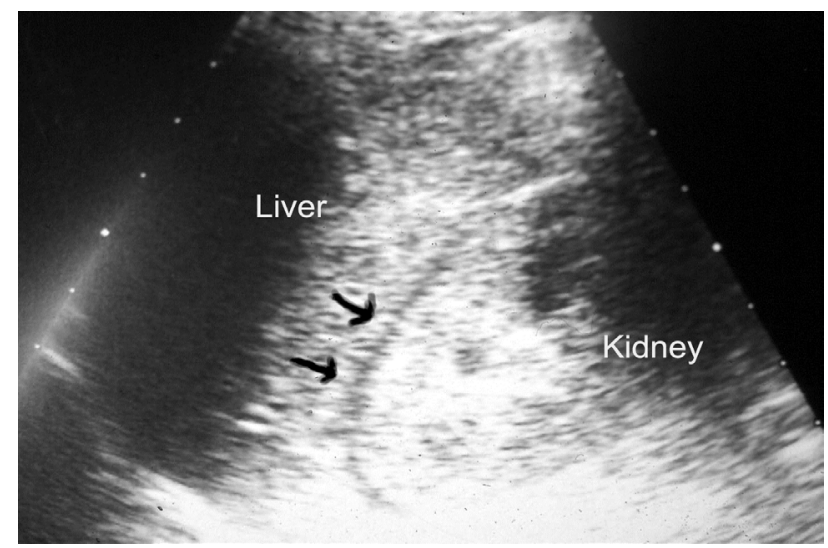

Figure 2: FAST examination shows fluid in Morison's pouch (arrows).

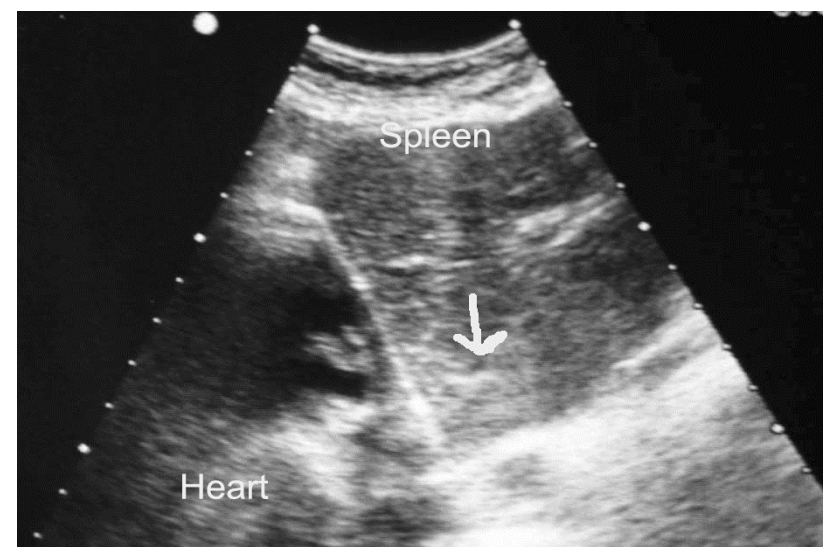

Figure 3: FAST examination shows hyperechoic areas on the spleen from a contusion (arrow).

crepitus (Figure 1). His lung sounds were normal. His heart sounds were on the right side, but normal. His abdominal examination revealed tenderness over the left upper quadrant with guarding. His extremities and neurologic examination were normal.

His white blood cell (CBC) count was $18,600 / \mathrm{mm}^{3}$, hemoglobin $16.2 \mathrm{~g} / \mathrm{dl}$, hematocrit $46.6 \%$ and platelet $192,000 / \mathrm{mm}^{3}$. His comprehensive metabolic profile, cardiac enzymes, prothrombin time (PT), and activated thromboplastin time (aPTT) were normal.

His chest radiograph demonstrated $r$ right sided car-

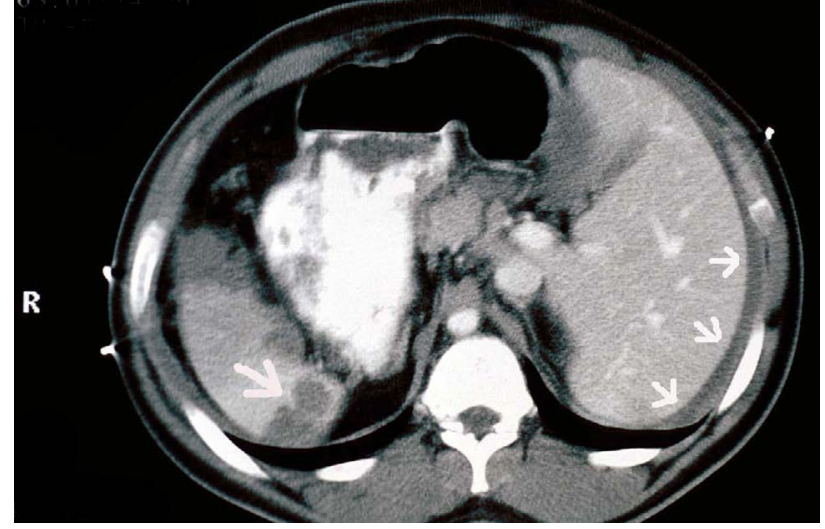

Figure 4: CT scan show perihepatic fluid (arrows on the right) and splenic contusion (arrow on the left).

diac apex. His focused assessment with sonography in trauma (FAST) examination revealed the presence of fluid in Morison's pouch in the left upper quadrant (Figure 2), contusion over the spleen in the right upper side (Figure 3), but no free fluid in the pelvis or pericardial fluid. His computed tomography scan (CT) demonstrated fluid around the liver without solid liver organ injury and multiple splenic contusions (Figure 4).

The patient was hospitalized and observed. He did well and was release 2 days later with no complications. He was seen in clinic 2 weeks later with no additional symptoms or complications.

\section{Discussion}

Dextrocardia (the heart being located on the right side of the thorax) was first seen and drawn by Leonardo da Vinci in 1452-1519. Hieronymus Fabricius ab Aquapendente is credited with describing situs inversus in the 1606, while Marco Severino described dextrocardia in 1643 [6,7]. Situs inversus is associated with a number of other conditions, such primary ciliary dyskinesia, also known as Kartagener's (sinusitis, bronchiectasis, and situs inversus) and multiple congenital heart disorders, especially transposition of the great arteries (TGA), atrial septal defect (ASD), ventricular septal defect (VSD), pulmonary valve stenosis, patent ductus arteriosus (PDA) and tetralogy of Fallot (TOF) $[8,9]$.

Situs denotes the position of the cardiac atria and viscera [10]. Situs solitus is the normal position, while situs inversus is the mirror image of situs solitus. Situs inversus can be classified further into situs inversus with levocardia or situs inversus with dextrocardia. In levocardia, the base-to-apex axis points to the left, and in dextrocardia, the axis is reversed. When situs cannot be determined, the patient is said to have situs ambiguous or heterotaxy. In these patients, the liver may be positioned in the midline, the spleen may be absent or may have multiple splenic tissue, the atrial morphology may be unclear, and the bowel may be malrotated. Often, structures that are normally unilateral are either duplicated or absent. Situs ambiguous tends toward 
symmetric morphology of normally asymmetric structures, termed isomerism. Two variants seen with situs ambiguous are asplenia syndrome and polysplenia syndrome. The asplenia syndrome is characterized by bilateral right-sidedness (right isomerism), whereas bilateral left-sidedness (left isomerism) is the hallmark of polysplenia syndrome.

Situs inversus is associated more commonly with dextrocardia [8]. A 3\% to 5\% incidence of congenital heart disease is observed in situs inversus with dextrocardia, particularly with transposition of the great vessels $[8,9]$. Of these patients, $80 \%$ have a right-sided aortic arch. Situs inversus with levocardia is rare, and it is almost always associated with congenital heart disease [5].

Situs abnormalities may be recognized first by using plain radiography or ultrasonography [2,11-14]. In most patients with situs inversus, chest radiography shows dextrocardia, with the cardiac apex pointing to the right and the aortic arch and stomach bubble located on the right as well. Ultrasound easily displays the location of the liver in the left upper quadrant and that the spleen is in the right upper quadrant [15]. Trauma in patients with situs inversus has only rarely been reported [1623]. To our knowledge there are no case reports of the FAST examination with situs inversus. However, computed tomography (CT) scanning is the preferred examination for the definitive diagnosis of situs inversus with dextrocardia. CT scanning provides great anatomic detail for confirming visceral organ position, cardiac apical position, and great vessel branching. Magnetic resonance imaging (MRI) is usually reserved for difficult cases, where radiation exposure is a concern or for patients with associated complex cardiac anomalies [24]. This imaging modality is particularly helpful in diagnosing atrial situs and in clarifying the morphology of complex congenital heart diseases.

Surgical management in situs inversus totalis is difficult because of the altered anatomy. Anesthetic complications may arise in these patients because of the high incidence of congenital heart diseases.

\section{Conclusion}

Situs inversus is a rare anomaly and when confronted with a patient with trauma, their diagnosis may be confounded since location of symptoms may be atypical due to the anatomic abnormality. Expedient diagnosis of solid organ injury in these patients is important, since treatment may be affected according to which organ is injured.

\section{References}

1. Mayo CW, Rice RG (1949) Situs inversus totalis: A statistical review of data on 76 cases with special reference to disease of the biliary tract. Arch Surg 58: 724-730.

2. Lee SE, Kim HY, Jung SE, Lee SC, Park KW, et al. (2006) Situs anomalies and gastrointestinal abnormalities. J Pediatr Surg 41: 1237-1242.
3. Tiwari A, MacMull S, Fox S, Jacob SA (2006) Left sided abdominal pain in a patient with situs inversus. Clin Anat 19: 154-155.

4. Kumar S, Fusai G (2007) Laparoscopic cholecystectomy in situs inversus totalis with left-sided gall bladder. Ann R Coll Surg Engl 89: 16-18.

5. Gindes L, Hegesh J, Barkai G, Jacobson JM, Achiron R (2007) Isolated levocardia: Prenatal diagnosis, clinical importance, and literature review. J Ultrasound Med 26: 361-365.

6. Cleveland M (1926) Situs inversus viscerum: Anatomic study. Arch Surg 13: 343-368.

7. Lineback PE (1920) An extraordinary case of situs inversus totalis. JAMA 75: 1775-1778.

8. Maldjian PD, Saric M (2007) Approach to dextrocardia in adults: Review. AJR Am J Roentgenol 188: S39-S49.

9. Grant RP (1958) The syndrome of dextroversion of the heart. Circulation 18: 25-36.

10. Winer-Muram HT (1995) Adult presentation of heterotaxic syndromes and related complexes. J Thorac Imaging 10: 43-57.

11. Applegate KE, Goske MJ, Pierce G, Murphy D (1999) Situs revisited: Imaging of the heterotaxy syndrome. Radiographics 19: 837-852.

12. Silverman $\mathrm{NH}$ (1983) An ultrasonic approach to the diagnosis of cardiac situs, connections, and malpositions. Cardiol Clin 1: 473-486.

13. Tonkin IL, Tonkin AK (1982) Visceroatrial situs abnormalities: Sonographic and computed tomographic appearance. AJR Am J Roentgenol 138: 509-515.

14. Partridge $\mathrm{J}$ (1979) The radiological evaluation of atrial situs. Clin Radiol 30: 95-103.

15. Chandramouly BS, Kihm RH, Flesh LH (1980) Dextrocardia with total situs inversus. Radionuclide imaging and ultrasonography of liver and spleen. N Y State J Med 80: 655-657.

16. Jones DJ, Duam RE (1987) Transection of the retrohepatic vena cava in a case of total situs inversus following blunt trauma. J R Army Med Corps 133: 161-162.

17. Roynard JL, Fosse JP, Cohen Y, Destable MD, Hoang The Dan P (1996) Survival following left ventricular rupture and dextrorotation of the heart due to blunt chest trauma. Intensive Care Med 22: 609.

18. Kullick DM, Park SJ, Harrison BS, Shunway SJ (1988) Traumatic aortic and diaphragmatic rupture in a patient with dextrocardia and situs inversus: Case report. J Trauma 45: 397-399.

19. Ho AM (1999) Traumatic aortic and diaphragmatic rupture in a patient with situs inversus. J Trauma 46: 530-531.

20. Kamath B, Chatterjee AS, Chandorkar I (2015) Splenic injury in situs inversus totalis - a surgical challenge. J Clin Diagn Res 9: PD01- PD02.

21. Srivastva V, Kumar P, Dosar S (2010) A case of splenic rupture in patient of situs inversus. Indian J Surg 72: 326-327.

22. Olasehinde O, Owojuyigbe AM, Adisa AO, Awowole IO (2014) Incidental finding of complete situs inversus in a polytraumatized adult. Afr J Med Med Sci 43: 183-186.

23. Pan MS, Shiao CC, Chang YM (2015) When hepatoma rupture happens in situs inversus totalis: Side matters. Acta Clin Belg 70: 149-150.

24. Yoo SJ, Kim YM, Choe YH (1999) Magnetic resonance imaging of complex congenital heart disease. Int $\mathrm{J}$ Card Imaging 15: 151-160. 